\title{
Structural, Optical, and Chemical Properties of Cadmium Phosphate Glasses
}

\author{
Jae-Yeop Chung, Jong-Hwan Kim, Su-Yeon Choi, Hyun-Joon Park, Moon-Kyung Hwang, \\ Yoon-Ki Jeong, and Bong-Ki Ryu ${ }^{\dagger}$ \\ Department of Materials Science and Engineering, Pusan National University, Busan 609-735, Korea
}

(Received January 20, 2015; Accepted February 11, 2015)

\begin{abstract}
In this study, we prepared cadmium phosphate glasses with various compositions, given by $x$ CdO- $(100-x) \mathrm{P}_{2} \mathrm{O}_{5}(x=10-55$ mol\%), and analyzed their Fourier transform infrared spectra, dissolution rate, thermal expansion coefficient, glass transition temperature, glass softening temperature, and optical band gap. We found that the thermal expansion coefficient and dissolution rate increased while the glass transition temperature and glass softening temperature decreased with increasing $\mathrm{CdO}$ content. These results suggest that $\mathrm{CdO}$ acts as a network modifier in binary phosphate glass and weakens its structure.
\end{abstract}

Key words : Fourier transform infrared spectroscopy, Optical band gap energy, Dissolution rate, Phosphate glass, Non-bridging oxygen, Network modifier

\section{Introduction}

$\mathrm{P}$ hosphate glasses have a number of unusual properties that have attracted attention over the years. More than a century ago, it was found that phosphate glasses have low dispersion, high refractive index, and high UV transparency when compared to silicate glasses. ${ }^{1,2)}$ Moreover, phosphate glasses are particularly attractive hosts because they can accommodate large concentrations of active ions without any deterioration in their useful properties. Recently, phosphate glasses with high concentrations of transition metals have been attracting considerable interest because of their semiconducting properties and optical absorption in the visible region, which results in glass coloration. Among transition metals, cadmium is used as a coloring, phase separation, and photoconductive material. Moreover, cadmium is used in quantum dot solar cells because of its high density and low binding energy. Cadmium-phosphate-based glasses have been used as matrices for the growth of cadmium selenide quantum dots; however, little is known of the structure of binary cadmium phosphate glasses. In the present study, we changed the composition of cadmium phosphate glasses represented by $x \mathrm{CdO}-(100-x) \mathrm{P}_{2} \mathrm{O}_{5}(x=10-55 \mathrm{~mol} \%)$ and observed the chemical durability as well as structural, optical, and thermal properties of these glasses.

${ }^{\dagger}$ Corresponding author : Bong-Ki Ryu

E-mail : bkryu@pusan.ac.kr

Tel : +82-51-510-3200 Fax : +82-51-571-8838

\section{Experimental Procedure}

\subsection{Glass preparation}

Glass samples with the composition $x \mathrm{CdO}-(100-x) \mathrm{P}_{2} \mathrm{O}_{5}$ $(x=10,20,30,40,45,50$, and $55 \mathrm{~mol} \%)$ were prepared using $\mathrm{NH}_{4} \mathrm{H}_{2} \mathrm{PO}_{4}$ (Junsei Chemical Co., Japan) and CdO (Junsei Chemical Co., Japan).

All the glass samples were prepared in 45-g batches; the constituents were mixed together by grinding them repeatedly to obtain homogeneity. This mixture (45 g) was melted in an alumina crucible in an electrically heated furnace under ordinary atmospheric conditions at a temperature of $300^{\circ} \mathrm{C}$ for about $2 \mathrm{~h}$ in order to evaporate ammonia, carbonate, and water from the batch and to minimize the tendency of the glass to undergo subsequent phosphate volatilization. The temperature was then raised gradually to $1100^{\circ} \mathrm{C}$ and maintained at this value for $90 \mathrm{~min}$ to homogenize the melt. The obtained melt was quenched in a stainless-steel-plated vessel; the glass was then annealed at $500^{\circ} \mathrm{C}$ for $3 \mathrm{~h}$ to relieve mechanical stresses and to lessen the tendency of the freshly formed glass to crack. ${ }^{3)}$

\subsection{Measurements}

The amorphous nature of the samples was confirmed by X-ray diffractometry (XRD, Rigaku-Ultima IV). The thermophysical properties of the prepared glass samples were measured using a model Q400 thermal mechanical analyzer (TA Instruments) at a heating rate of $10^{\circ} \mathrm{C} / \mathrm{min}$. From the obtained curves, the linear coefficient of thermal expansion (a) of the glass samples was obtained as the mean value in the temperature range $100-300^{\circ} \mathrm{C}$. The glass transition temperature $\left(\mathrm{T}_{\mathrm{g}}\right)$ was determined from the change in the slope of the elongation vs. temperature plot. The glass soft- 
ening temperature $\left(\mathrm{T}_{\mathrm{d}}\right)$ was obtained from the maximum of the expansion curve. The chemical durability of the glass samples was evaluated from their dissolution rates (DRs) in distilled water at $60^{\circ} \mathrm{C}$. For this, glass cubes were placed in distilled water for $72 \mathrm{~h}$. The DR was calculated from the expression $\mathrm{DR}=\Delta \mathrm{w} / \mathrm{S} \mathrm{t}$, where $\Delta \mathrm{w}$ is the weight loss (g), $\mathrm{S}$ is the sample area $\left(\mathrm{cm}^{2}\right)$ before the dissolution test, and $\mathrm{t}$ is the dissolution time $(\mathrm{min})^{4)}$. The structure of the glass samples was analyzed by Fourier transform infrared (FTIR) spectroscopy ( $\mathrm{KBr}$, Spectrum GX, 400-1400 $\mathrm{cm}^{-1}$ ). The optical transmittance and absorption of all glass samples were investigated using a UV-vis spectrometer (8453, Agilent Technologies).

\section{Results and Discussion}

\subsection{Glass-forming region}

Figure 1 shows the XRD data for the prepared $x \mathrm{CdO}-$

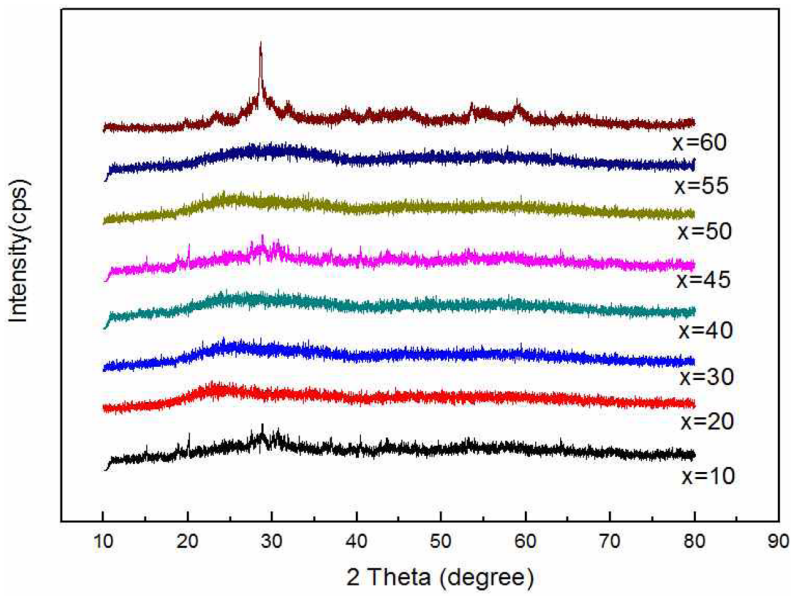

Fig. 1. $\mathrm{XRD}$ data for $x \mathrm{CdO}-(100-x) \mathrm{P}_{2} \mathrm{O}_{5}$ glasses. $(100-x) \mathrm{P}_{2} \mathrm{O}_{5}$ glasses. It can be observed that a crystallization peak appears when the $\mathrm{CdO}$ content is more than 60 mol\%. Moreover, a visual inspection revealed that the glasses were opaque when the $\mathrm{CdO}$ content was $60 \mathrm{~mol} \%$.

Therefore, in this paper, only cadmium concentrations in the range $10-55 \mathrm{~mol} \%$ are discussed.

\subsection{Structural properties}

The IR spectra of the prepared $x \mathrm{CdO}-(100-x) \mathrm{P}_{2} \mathrm{O}_{5}$ glasses are shown in Fig. 2. $\mathrm{A} \mathrm{PO}_{2}$ asymmetric stretching vibration $\left(\mathrm{V}_{\mathrm{as}}\right)$ band, $\mathrm{PO}_{2}$ symmetric stretching vibration $\left(\mathrm{V}_{\mathrm{s}}\right)$ band, $\mathrm{V}_{\mathrm{as}}$ band for $\mathrm{P}-\mathrm{O}-\mathrm{P}$ groups, and $\mathrm{V}_{\mathrm{s}}$ band for $\mathrm{P}-\mathrm{O}-$ $\mathrm{P}$ groups can be observed near 1270, near 1160, near 890, and near $720-775 \mathrm{~cm}^{-1}$, respectively. ${ }^{5)}$ It can be observed that in the $720-775 \mathrm{~cm}^{-1}$ region, the wavenumber decreases gradually with increasing $\mathrm{CdO}$ content. On the basis of this observation, we were able to confirm that cadmium breaks $\mathrm{P}-\mathrm{O}-\mathrm{P}$ bonds and increases the number of non-bridging oxygen (NBO) atoms ${ }^{6-9)}$. Further, it can be observed that the small peak near $1200 \mathrm{~cm}^{-1}$ becomes sharper with increasing $\mathrm{CdO}$ content. The reason for this is that the breakage of $\mathrm{P}$ $\mathrm{O}-\mathrm{P}$ bonds results in the occurrence of symmetric and asymmetric stretching vibrations of $\mathrm{PO}_{2}$. Thus, we can conclude that $\mathrm{CdO}$ acts as a network modifier in binary phosphate glasses.

Van Wazer explained the structure of $\mathrm{P}_{2} \mathrm{O}_{5}$ in phosphate glass using $\mathrm{Q}$ terminology ${ }^{10)}$. Short-range structures of binary phosphate glasses can be described by the type and concentration of $\left[\mathrm{PO}_{4}\right]$ species and can be denoted by $\mathrm{Q}^{\mathrm{n}}$ $(0 \leq \mathrm{n} \leq 3)$, where $\mathrm{n}$ is the number of bridging oxygen atoms per tetrahedron. Fig. 3 shows $Q^{0}, Q^{1}, Q^{2}$, and $Q^{3}$ (number of bridging oxygen atoms: $0,1,2$, and 3 , respectively).

In binary phosphate glasses, the fractions of $\mathrm{Q}^{2}$ and $\mathrm{Q}^{3}$ are given by the following simple expression:

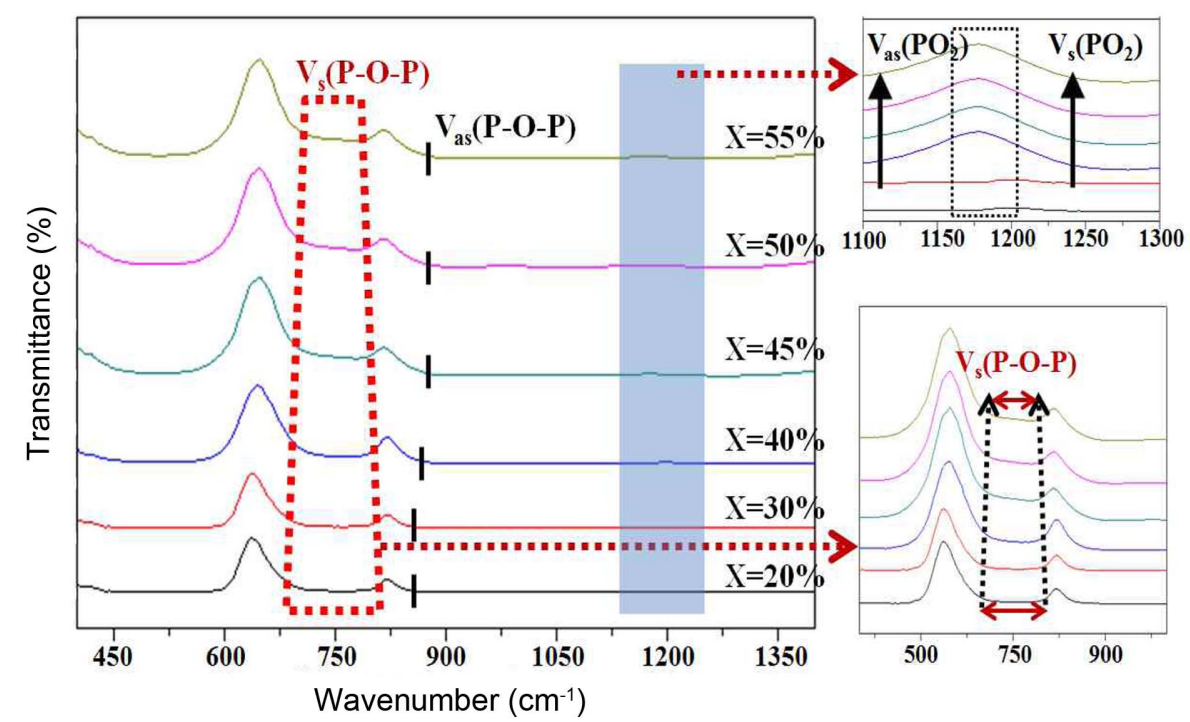

Fig. 2. Infrared spectra of $x \mathrm{CdO}-(100-x) \mathrm{P}_{2} \mathrm{O}_{5}$ glasses. 


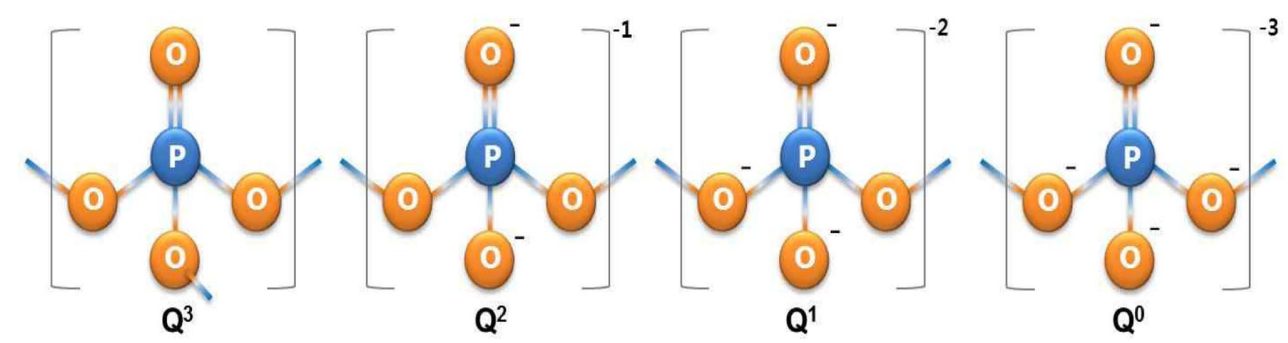

Fig. 3. Structure of phosphate glass.

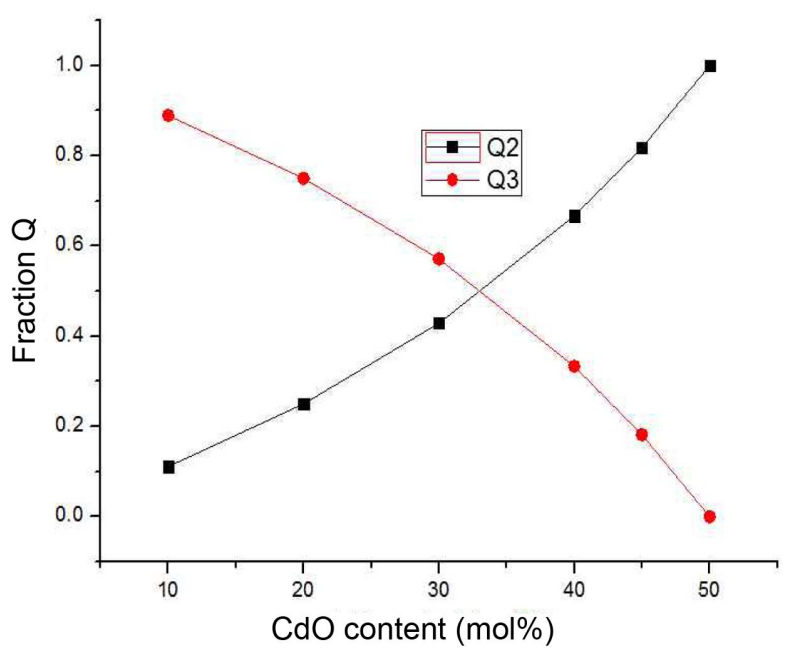

Fig. 4. Theoretical values of number of bridging oxygen atoms.

$$
\mathrm{f}\left(\mathrm{Q}^{2}\right)=\frac{x}{1-x}, \mathrm{f}\left(\mathrm{Q}^{3}\right)=\frac{1-2 x}{1-x}, x \leq 50
$$

According to this expression, $\mathrm{Q}^{3}$ decreases and $\mathrm{Q}^{2}$ increases with increasing $\mathrm{CdO}$ content. When $\mathrm{R}_{2} \mathrm{O}$ is more than $50 \mathrm{~mol} \%$, the fractions of $\mathrm{Q}^{1}$ and $\mathrm{Q}^{2}$ are given by the following expression:

$$
\begin{aligned}
& x \mathrm{R}_{2} \mathrm{O}\left(\text { or } \mathrm{R}^{\prime} \mathrm{O}\right)-(1-x) \mathrm{P}_{2} \mathrm{O}_{5}, \\
& \mathrm{f}\left(\mathrm{Q}^{2}\right)=\frac{2-3 x}{1-x}, \mathrm{f}\left(\mathrm{Q}^{1}\right)=\frac{2 x-1}{1-x}, 50 \leq x \leq 67
\end{aligned}
$$

It is possible to know that $\mathrm{Q}^{2}$ decreases and $\mathrm{Q}^{1}$ increases with increasing $\mathrm{CdO}$ content through Eq. (2).

Figure 4 shows the theoretically calculated values of the number of bridging oxygen atoms. On the basis of these results, we can conclude that increasing $\mathrm{CdO}$ content increases the number of NBO atoms. As a result, the glass structure is weakened by the presence of cadmium ions.

\subsection{Chemical durability}

Generally, the DR of glass increases when the glass structure becomes weaker. ${ }^{11,12)}$ Fig. 5 shows that the DR increases consistently with increasing $\mathrm{CdO}$ content. This is attributed to the replacement of $\mathrm{P}-\mathrm{O}-\mathrm{P}$ bonds by $\mathrm{P}-\mathrm{O}-\mathrm{Cd}$

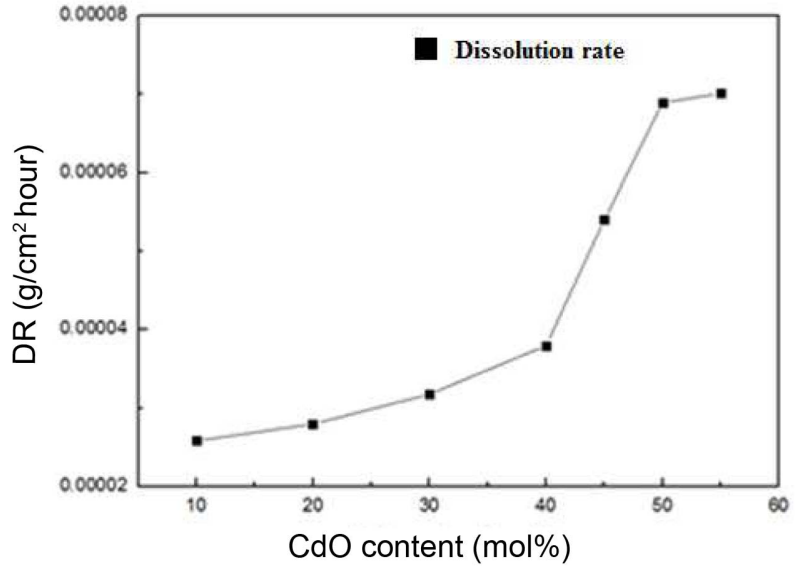

Fig. 5. Variations in dissolution rate of $x \mathrm{CdO}-(100-x) \mathrm{P}_{2} \mathrm{O}_{5}$ glasses.

bonds; this replacement is accompanied by a decrease in chemical durability. These findings prove that the bonding forces inside the structural network weaken as a result of the formation of $\mathrm{P}-\mathrm{O}-\mathrm{Cd}$ bonds. This is because the strength of the $\mathrm{Cd}-\mathrm{O}$ bond $(236 \mathrm{kcal} / \mathrm{mol})$ is much lower than that of the $\mathrm{P}-\mathrm{O}$ bond $(599 \mathrm{kcal} / \mathrm{mol})$. Generally, a glass structure consists of both ionic and covalent bonding. However, as shown in Fig. 5, there is a rapid increase in DR when the $\mathrm{CdO}$ content is more than $40 \mathrm{~mol} \%$. The reason for this result may be ascribed to the exponential increase of ionic bonding when $\mathrm{CdO}$ content is more than $40 \mathrm{~mol} \%$. Increase of ionic bonding weakens the glass structure and rapidly decreases the chemical durability. Rapid change in property when $\mathrm{CdO}$ content is more than $40 \mathrm{~mol} \%$ was further confirmed through analysis of the optical property.

\subsection{Optical properties}

Figure 6 shows the optical energy band gap of the prepared glasses as measured by UV-vis spectroscopy. The optical energy band gap was calculated using the absorption coefficient of the glasses. The Lambert-Beer equation ( $T /$ $\left.T_{0}=e^{-\alpha d}\right)$ and Tauc's equation $\left(\alpha(v) h v \approx\left(h v-E_{g}\right)^{n}\right)$ were used $^{13)}$, and the calculated values were plotted using an indirect method. An increase in the $\mathrm{CdO}$ content resulted in the optical edge shifting to the left and the optical band gap decreasing. This is because the donor center is increased by NBO atoms, thereby leading to a decrease in the optical 


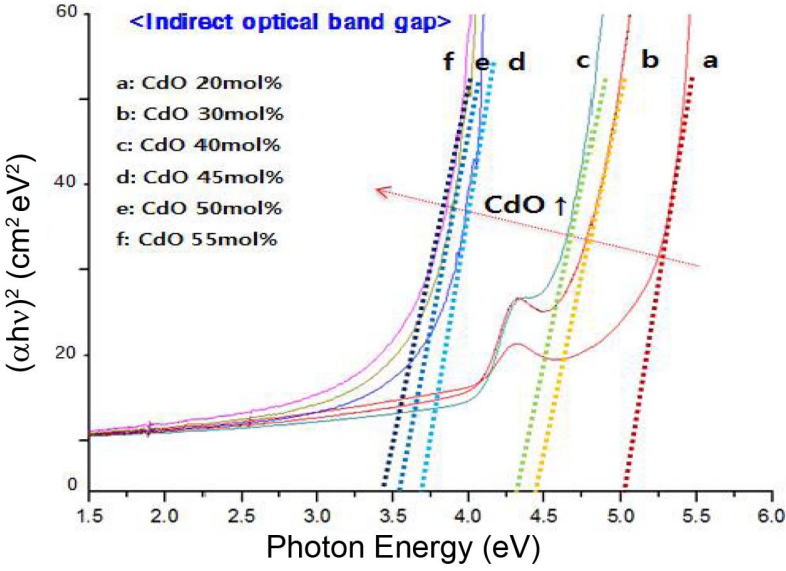

Fig. 6. Variations in optical band gap of $x \mathrm{CdO}-(100-x)$ $\mathrm{P}_{2} \mathrm{O}_{5}$ glasses

band gap. Further, a rapid decrease in the band gap energy was observed when the $\mathrm{CdO}$ content was more than $40 \%$. This result is similar to the results of the analysis of the chemical property. Abrupt changes in the optical band gap energy mean that NBO atoms increase rapidly when $\mathrm{CdO}$ content is more than $40 \mathrm{~mol} \%$. In general, ionic bonding increases when NBO atoms that can participate in ionic bonding increase ${ }^{14}$. For these reasons, it is expected that covalent bonding decreases sharply and ionic bonding begins to increase radically when $\mathrm{CdO}$ content is more than $40 \mathrm{~mol} \%$.

\subsection{Thermal properties}

Figure 7 shows the dependences of $a, T_{g}$, and $T_{d}$ on the CdO content of the prepared glasses. It can be observed that a increases, whereas $\mathrm{T}_{g}$ and $\mathrm{T}_{d}$ decrease with increasing $\mathrm{CdO}$ content. In general, a increases when the glass structure becomes weaker. On the basis of Fig. 7, it can be concluded that the glass structure is weakened by the presence of $\mathrm{CdO}$.

\section{Conclusion}

The purpose of this study was to identify vitrification areas in cadmium phosphate glasses and analyze the structural characteristics, chemical durability, and optical and thermal properties of these glasses. It was found that increasing the $\mathrm{CdO}$ content resulted in the breakage of $\mathrm{P}-$ $\mathrm{O}-\mathrm{P}$ bonds and creation of NBO atoms. An increase in the number of NBO atoms weakened the glass structure. Further, increasing the $\mathrm{CdO}$ content also reduced the chemical durability, as well as the $\mathrm{T}_{\mathrm{g}}$ and $\mathrm{T}_{\mathrm{d}}$ values of the glasses. An increase in the number of $\mathrm{NBO}$ atoms reduced the optical band gap energy of the glasses. On the basis of the results obtained in this study, we can conclude that $\mathrm{CdO}$ acts as a network modifier in binary phosphate glasses and weakens its structure. In addition, it can be deduced that ionic bonding increases and covalent bonding decreases when the $\mathrm{CdO}$

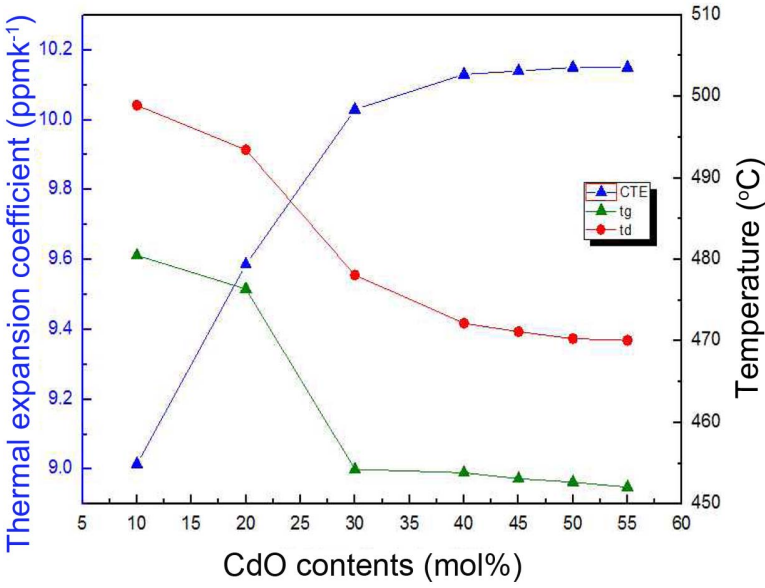

Fig. 7. Variations in thermal expansion coefficient, glass transition temperature, and glass softening temperature of $x \mathrm{CdO}-(100-x) \mathrm{P}_{2} \mathrm{O}_{5}$ glasses.

content is more than $40 \mathrm{~mol} \%$ through chemical and optical properties. However, this study did not involve sufficient quantitative investigation of ionic and covalent bonding of $\mathrm{Cd}-\mathrm{O}$, an issue that needs to be addressed in future research.

\section{Acknowledgments}

This research was financially supported by the Ministry of Education, Science Technology (MEST) and National Research Foundation of Korea(NRF) through the Human Resource Training Project for Regional Innovation.

\section{REFERENCES}

1. Y. A. Kim, K. H. Lee, T. H. Kim, Y. J. Jung, and B. K. Ryu, "Effect of $\mathrm{ZnO}$ Addition on the Photoluminescence of a Novel Phosphate Glass," Electron. Mater. Lett., 53 [1] 23235 (2008).

2. R. K. Brow, "Review: The Structure of Simple Phosphate Glasses", J. Non-Cryst. Solids, 263-264 [1] 1-28 (2002).

3. C. A. Hogarth and M. A. Ghauri, "The Preparation of Cadmium Phosphate and Cadmium Zinc Phosphate Glasses and Their Electrical and Optical Properties," J. Mater. Sci., 14 [7] 1641-46 (1979).

4. N. J. Kim, S. H. Im, D. H. Kim, D. K. Yoon, and B. K. Ryu, "Structure and Properties of Borophosphate Glasses," Electron. Mater. Lett., 6 [3] 103-06 (2011).

5. N. Kerkouri, M. Haddad, M. Et-tabirou, A. Chahine, and L. Laânab, "FTIR, Raman, EPR and Optical Absorption Spectral Studies on $\mathrm{V}_{2} \mathrm{O}_{5}$-doped Cadmium Phosphate Glasses," Physica B., 406 [17] 3142-48 (2011).

6. S. T. Reis, M. Karabulut, and D. E. Day, "Chemical Durability and Structure of Zinc-iron Phosphate Glasses," J.Non-Cryst. Solids, 292 [1-3] 150-07 (2001).

7. H. Doweidar, Y. M. Moustafa, K. El-Egili, and I. Abbas, "Infrared Spectra of $\mathrm{Fe}_{2} \mathrm{O}_{3}-\mathrm{PbO}-\mathrm{P}_{2} \mathrm{O}_{5}$ Glasses," Vib Spectrosc., 37 [1] 91-6 (2005). 
8. W. G. Choi, T. H. Kim, D. G. Gwoo, K. B. Kee, J. H. Kim, K. S. Han, and B. K. Ryu, "A Study of the Relationship between Structure and Properties of Cadmium Phosphate Glasses," Electron. Mater. Lett., 9 [1] 83-5 (2013).

9. T. H. Kim, D. G. Gwoo, J. H. Kim, W. G. Choi, K. S. Han, K. B. Kee, C. W. Hwang, and B. K. Ryu, "Relationship between Structure and Optical Properties in the CdO- $\mathrm{B}_{2} \mathrm{O}_{3}$ $\mathrm{SiO}_{2}$ Glass System," Electron. Mater. Lett., 8 [6] 617-20 (2012).

10. R. Hussin, D. Holland, and R. Dupree, "A MAS NMR Structural Study of Cadmium Phosphate Glasses," J. Non-Cryst. Solids., 298 [1] 32-42 (2002).

11. V. S. Molchanov and N. E. Prikhid, "Corrosion of Silicate Glasses by Alkaline Solutions," Russian Chem. Bull., 8 [6] 942-47 (1959).
12. D. H. Kim, C. W. Hwang, N. J. Kim, S. H. Im, D. G. Gwoo, T. H. Kim, J. M. Cha, and B. K. Ryu, "Effects of Substituting $\mathrm{B} 2 \mathrm{O} 3$ for $\mathrm{P} 2 \mathrm{O} 5$ on the Structure and Properties of SnOP2O5 Glass Systems(in Korean)," J. Korean Ceram. Soc., 48 [1] 63-8 (2011).

13. I. S. Ji, H. G. Park, Y. G. Kim, S. R. Kim, G. W. Nam, Y. S. Kim, and J. Y. Leem, "Structural and Optical Characteristics of CdxZn1-xO Thin Films with Various Cd Concentrations Prepared by a Dip-Coating Process," Korean J. Met. Mater., 52 [4] 271-76 (2014).

14. M. Zeyer, L. Montagne, V. Kostoj, G. Palavit, D. Prochnow, and C. Jaeger, " ${ }^{17} \mathrm{O}$ nuclear Magnetic Resonance Study of $\mathrm{Na}_{2} \mathrm{O}-\mathrm{P}_{2} \mathrm{O}_{5}$ Glasses," J. Non-Cryst. Solids, 311 [3] 223-32 (2002). 